CCl1 Basic Detector Performance

D. Lange, H. Manini, D. Wright, M. Cunningham, K. Vetter

June 6, 2005 
This document was prepared as an account of work sponsored by an agency of the United States Government. Neither the United States Government nor the University of California nor any of their employees, makes any warranty, express or implied, or assumes any legal liability or responsibility for the accuracy, completeness, or usefulness of any information, apparatus, product, or process disclosed, or represents that its use would not infringe privately owned rights. Reference herein to any specific commercial product, process, or service by trade name, trademark, manufacturer, or otherwise, does not necessarily constitute or imply its endorsement, recommendation, or favoring by the United States Government or the University of California. The views and opinions of authors expressed herein do not necessarily state or reflect those of the United States Government or the University of California, and shall not be used for advertising or product endorsement purposes.

This work was performed under the auspices of the U.S. Department of Energy by University of California, Lawrence Livermore National Laboratory under Contract W-7405-Eng-48. 
h4doc 10v1

UCRL-TR-

\title{
CCI1 Basic Detector Performance
}

\author{
David Lange, Hugh Manini, Douglas Wright \\ High Energy Physics Group, N Division \\ Mark Cunningham, Kai Vetter \\ Lawrence Livermore National Laboratory
}

June 1, 2005

\begin{abstract}
This document describes the basic detector performance for the CCI1 device, which consists of the $\mathrm{Si} 2$ and $\mathrm{Ge} 2$ detector components.
\end{abstract}

\section{Data}

Data were taken on 3-15-05 with a ${ }^{152} \mathrm{Eu}$ source at 30 degrees from the detector axis using the Measurement Studio version of the data-acquistion system. The data file is on the grims server as Morgan/cc1 data/CCI1-Eu152-30deg-1.txt, which is an uncompressed copy of data/CCI1/Measurement 01/Measurement 01 Data Set 05/Header.zip.

The trigger for these data required hits in both $\mathrm{Si}$ and Ge subdetectors. Only strips with an energy greater than some minimum value (approximately $25 \mathrm{keV}$ for $\mathrm{Ge}$ and $10 \mathrm{keV}$ for $\mathrm{Si}$ ) are read out; however for each strip that is above the minimum, the energy on the neighboring strips (one on each side) is recorded without any energy cut (and therefore can be less than the minimum). The energy threshold requirement is made before the energy calibration of the individual strips, so there is not a sharp cutoff in the data since the calibration varies from strip to strip.

The strips are numbered from 0 to 31 (37) for the silicon (germanium) detector. The so-called DC (AC) strips are vertical (horizontal) and measure the $\mathrm{x}(\mathrm{y})$ coordinate. 

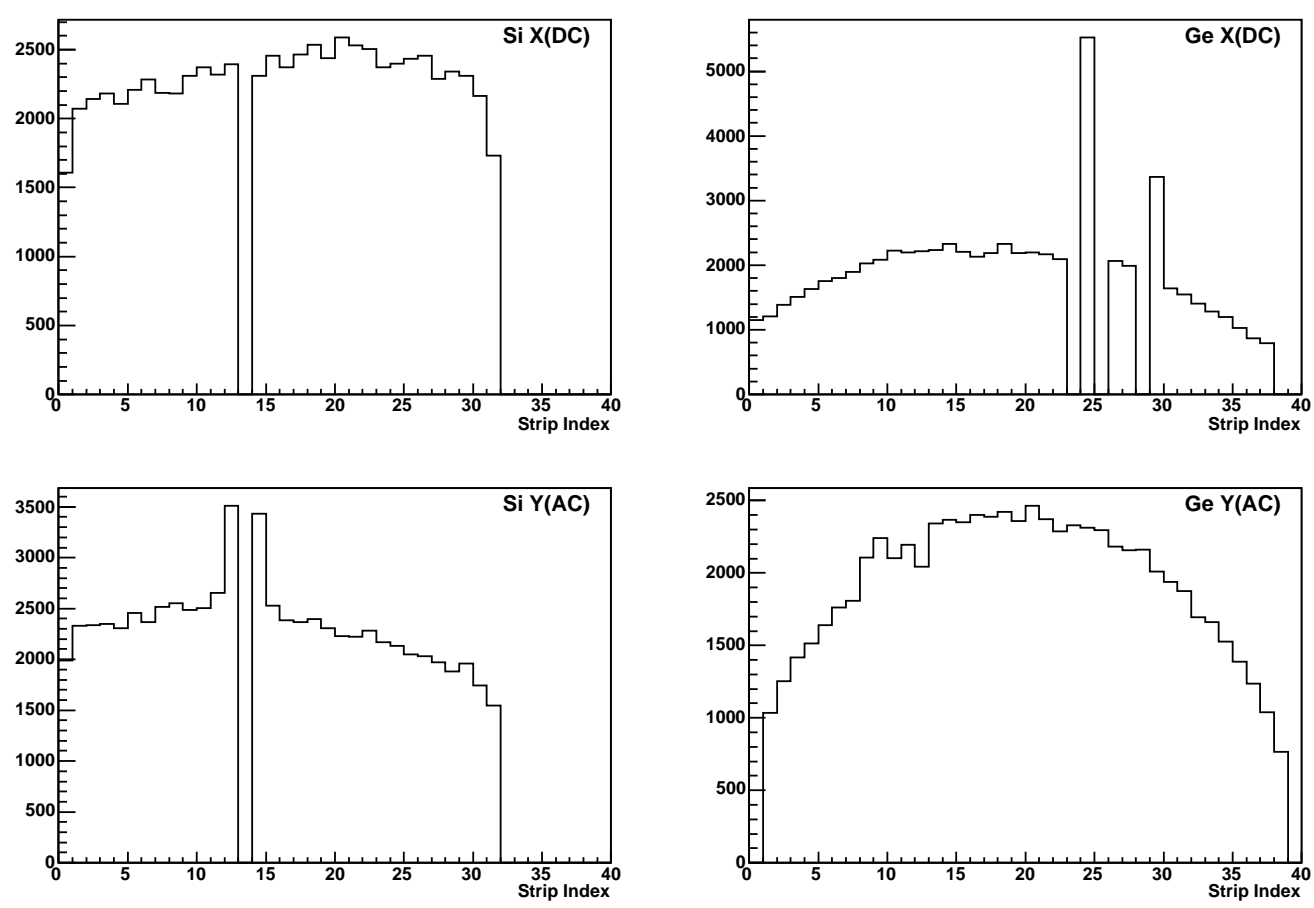

Figure 1: Strip index for all strips readout. ${ }^{152} \mathrm{Eu}$ source data.

\section{Occupancy}

The location (strip index) of all of the strips readout from each detector measurement axis from the first 50,000 events is given in Figure 1. In the Figure you see that strip 13 on the $\mathrm{X}$ side of the silicon is dead. On the Y side you see that strip 13 is probably not connected to the high voltage and that the charge is collected on the two neighboring strips, but not with full efficiency. In the germanium detector on the X side you see that strips 23, 24, and 25 are shorted to each other (not intentionally) and consequently only strip 24 is connected to a preamp and readout. Similarly strip 28 is shorted to strip 29 and only that channel is read out. On the Y side you see that the strips are shifted by one. This is an artifact introduced by the hardware and should be corrected in the offline analysis. 

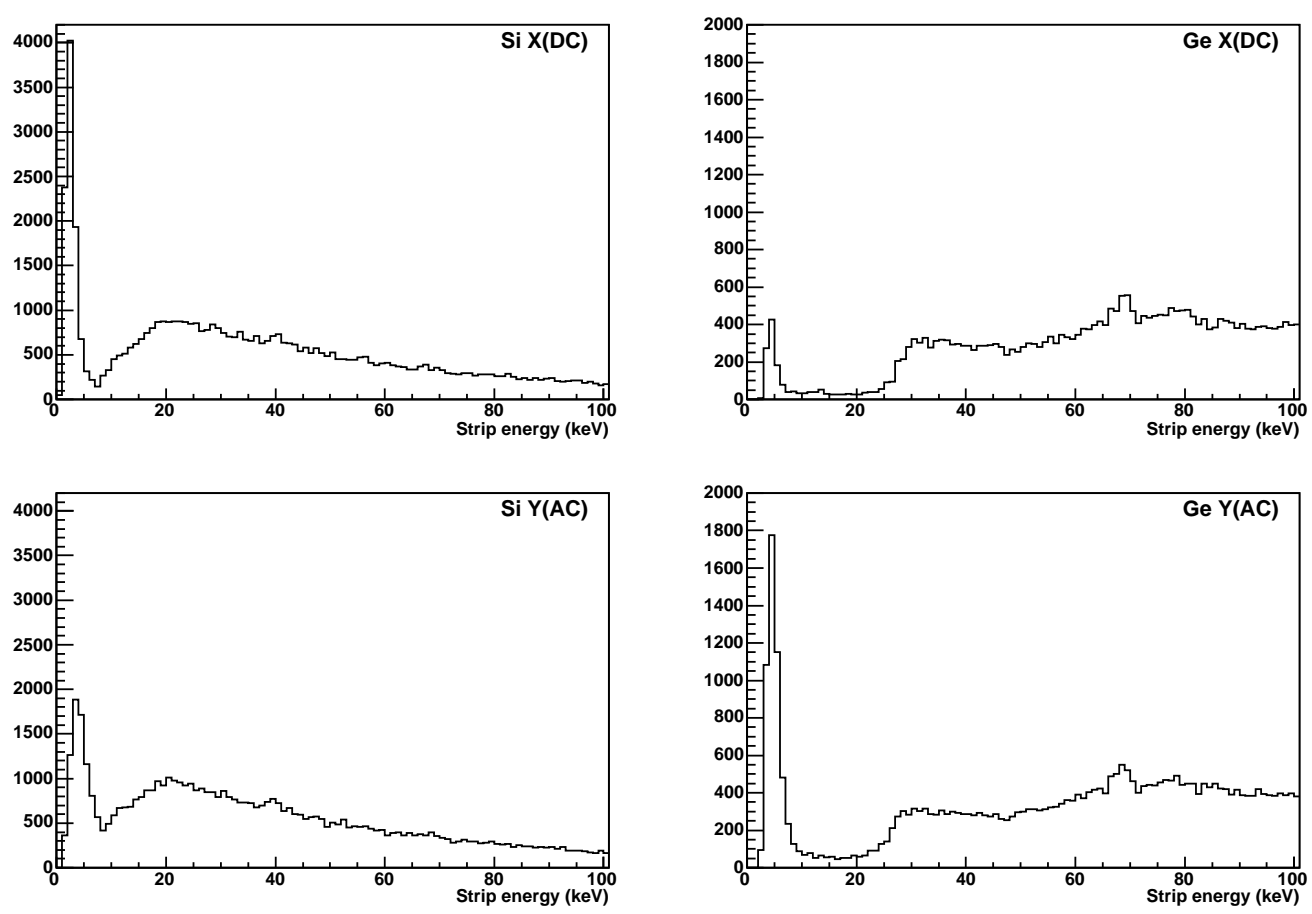

Figure 2: Histogram of strip energy for each detector read-out plane. ${ }^{152}$ Eu source data.

\section{Low Energy Strips}

There is a spike in the the individual strip energy distributions at around $5 \mathrm{keV}$, which can be attributed to transient signals on the strips next to those that collected significant charge. Figure 2 shows the individual strip energies below $100 \mathrm{keV}$ for each read-out plane. Note that the size of the peak at $5 \mathrm{keV}$ varies from plane to plane. Recall that only strips above a certain threshold energy are readout; but, the energy of its immediate neighbors are also recorded without applying this threshold requirement. 

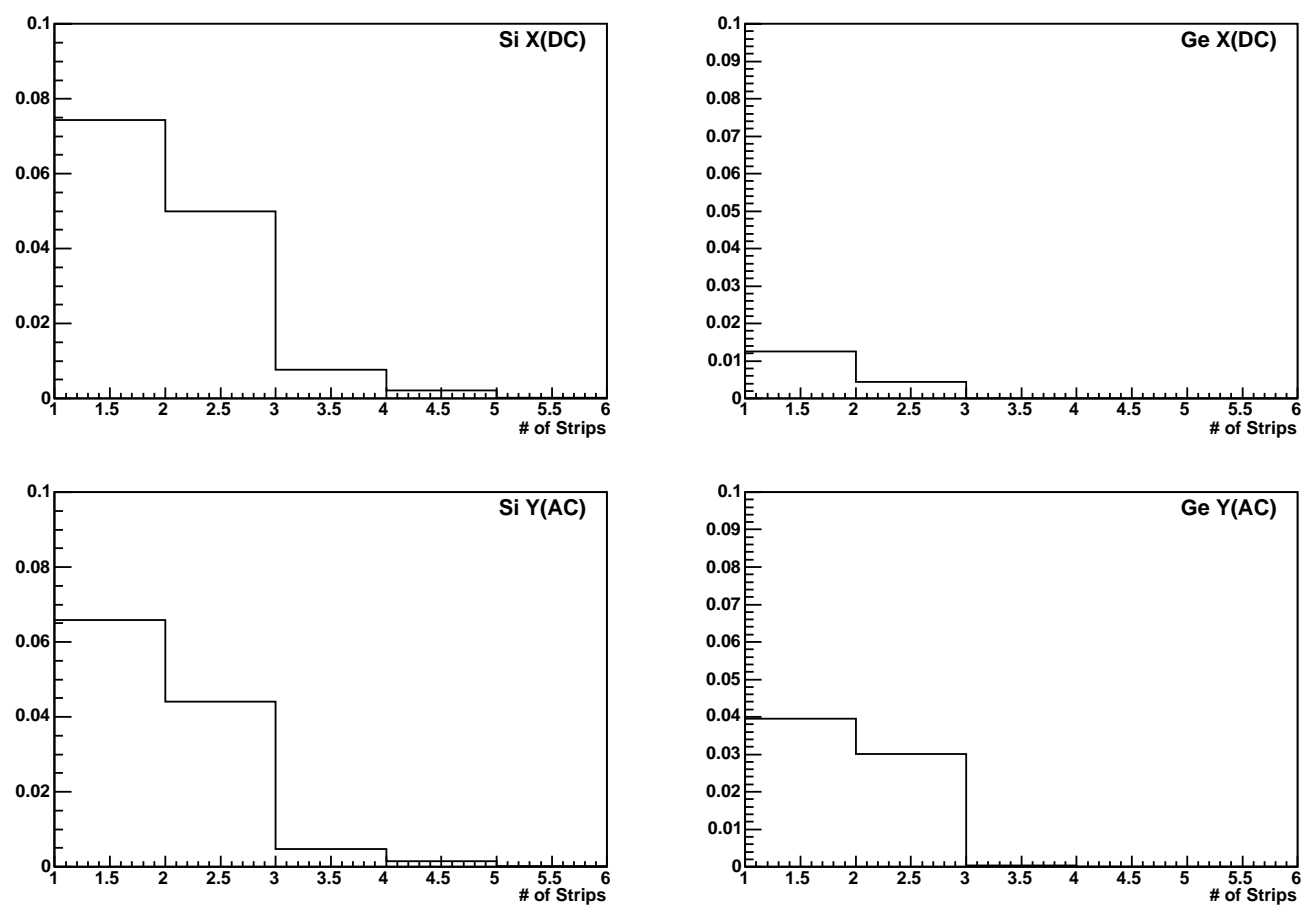

Figure 3: Fraction of events containing one or more low-energy strips. The total fraction $(\mathrm{X} / \mathrm{Y}$ side) is $13.5 \% / 11.6 \%$ for $\mathrm{Si}$ and $1.7 \% / 7.1 \%$ for $\mathrm{Ge}$.

Less than $15 \%$ of the events contain one or more of these low-energy strips $(E<10 \mathrm{keV})$, see Figure 3; but there seems to be a disparity between the number that appear in the $\mathrm{X}$ and $\mathrm{Y}$ sides of the germanium detector. 

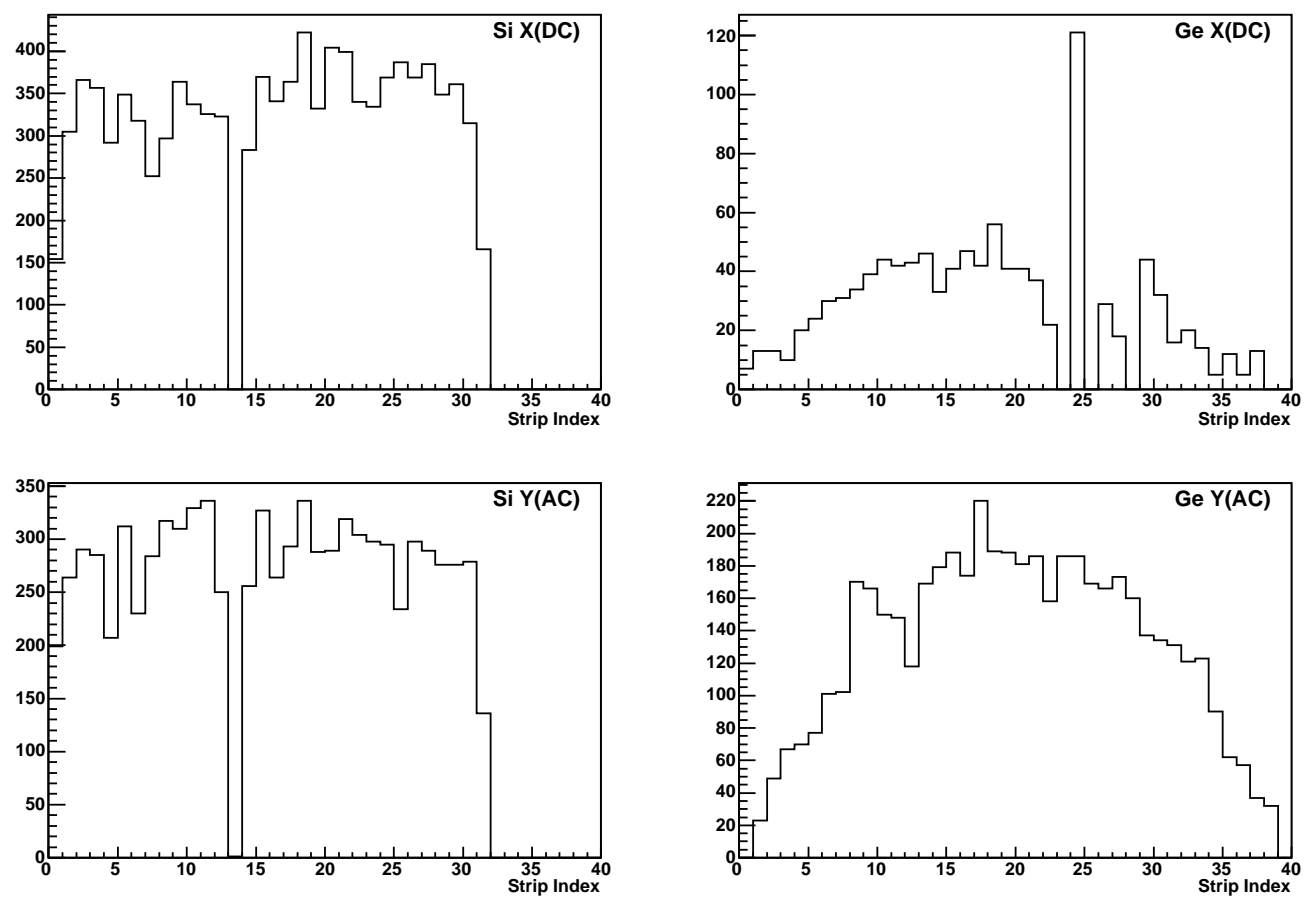

Figure 4: Strip index for all strips with energy less than $10 \mathrm{keV} .{ }^{152} \mathrm{Eu}$ source data.

These low-energy strips have the same occupancy as the rest of the data, as shown in Figure 4, and are almost always associated with another strip with large energy. Figure 5 shows the distance, measured in number of strips, from the low-E strip to the closest neighber that has non-zero energy. Nearly all low-E strips are immediately next to (a distance of exactly one) to a non-zero strip. The energy of this closest neighbor is plotted in Figure 6, where the entry in the histogram is weighted by the number of low-E strips in the event and is overlayed with the overall energy distribution for all strips. From this figure one sees that the low-E strips are typically associated with strips that have large energy deposition. 

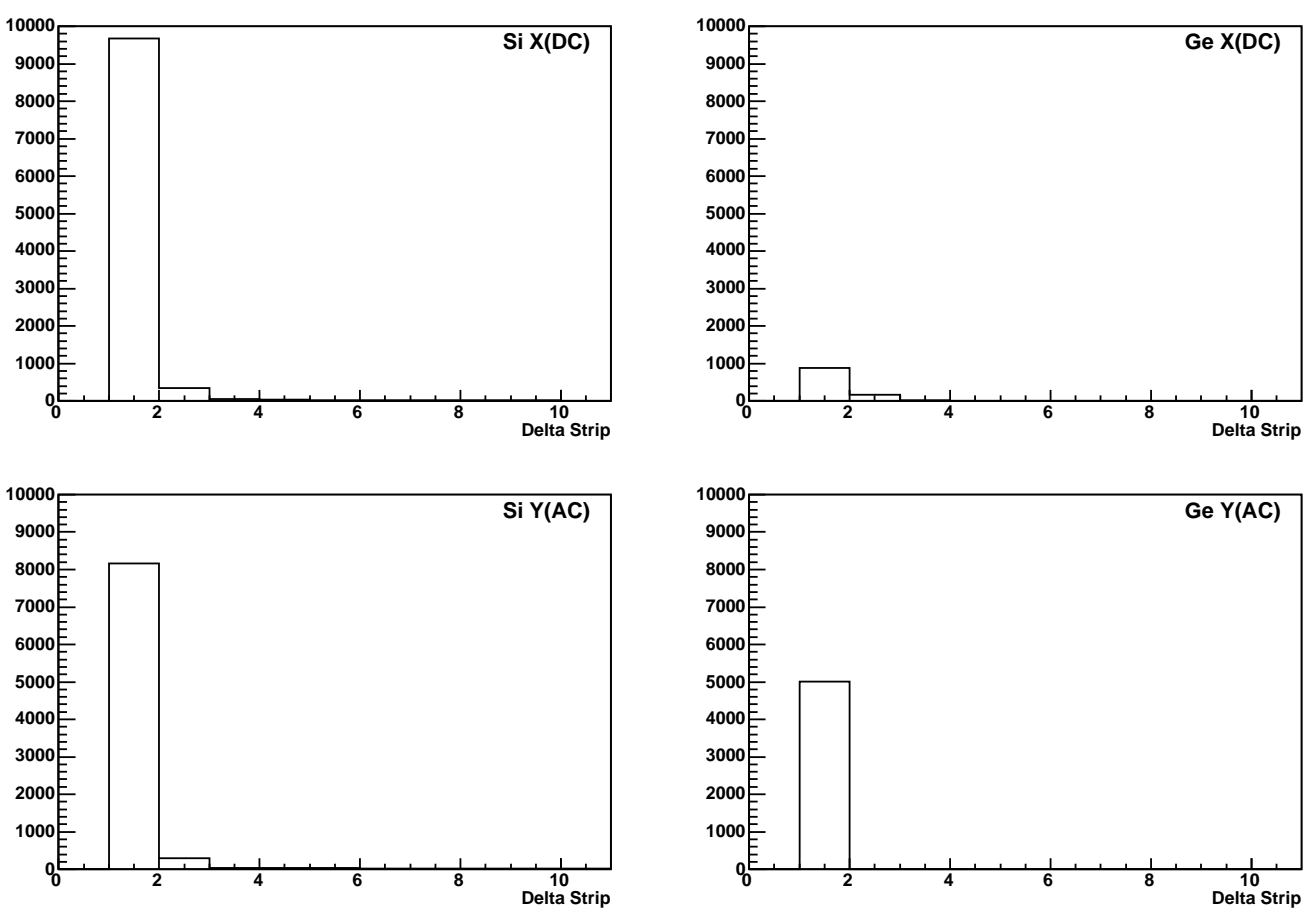

Figure 5: Distance (measured in strips) to the nearest strip in the same event with some non-zero energy.
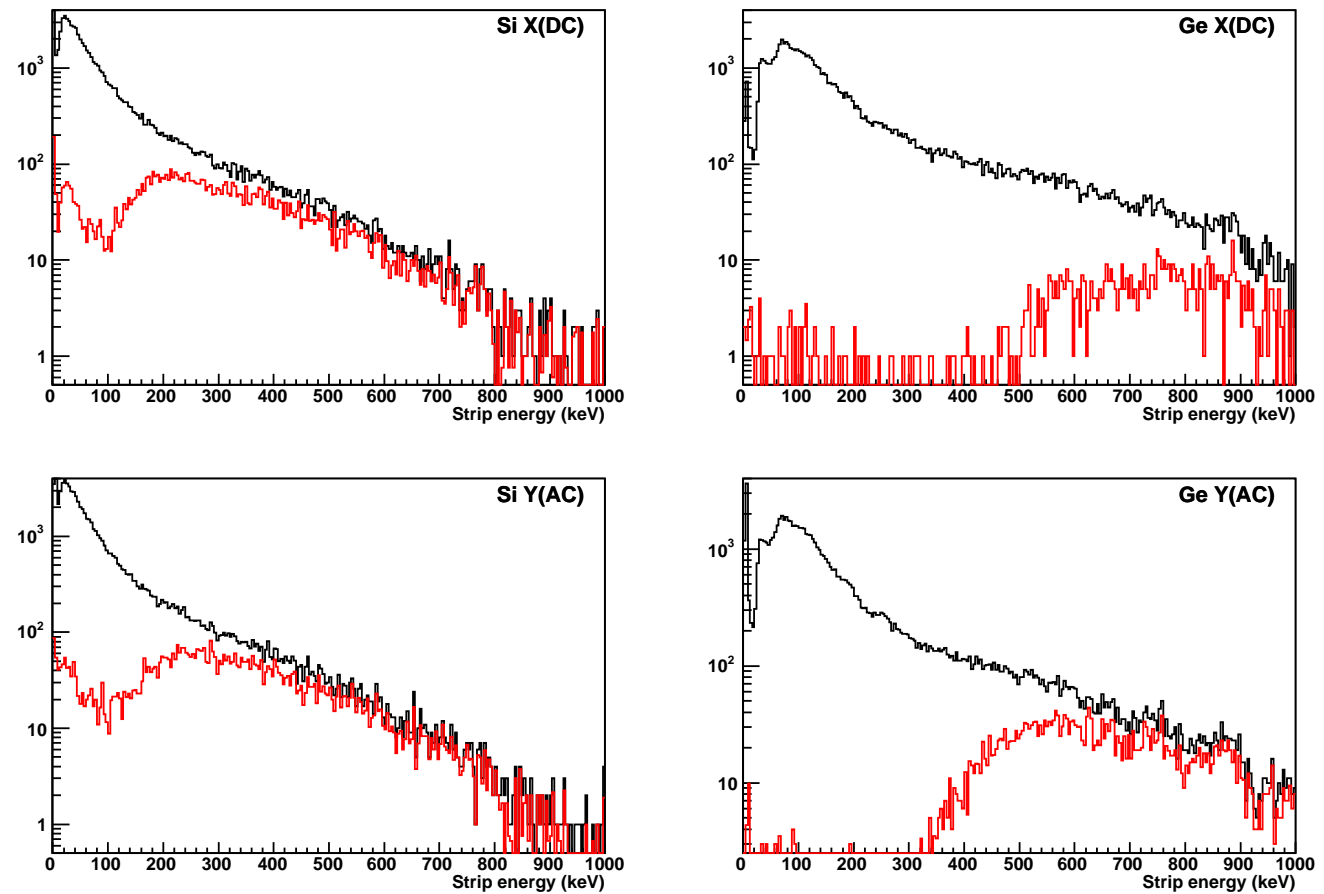

Figure 6: Energy of strip closest to the low-energy strip (red) compared to all strips (black). 

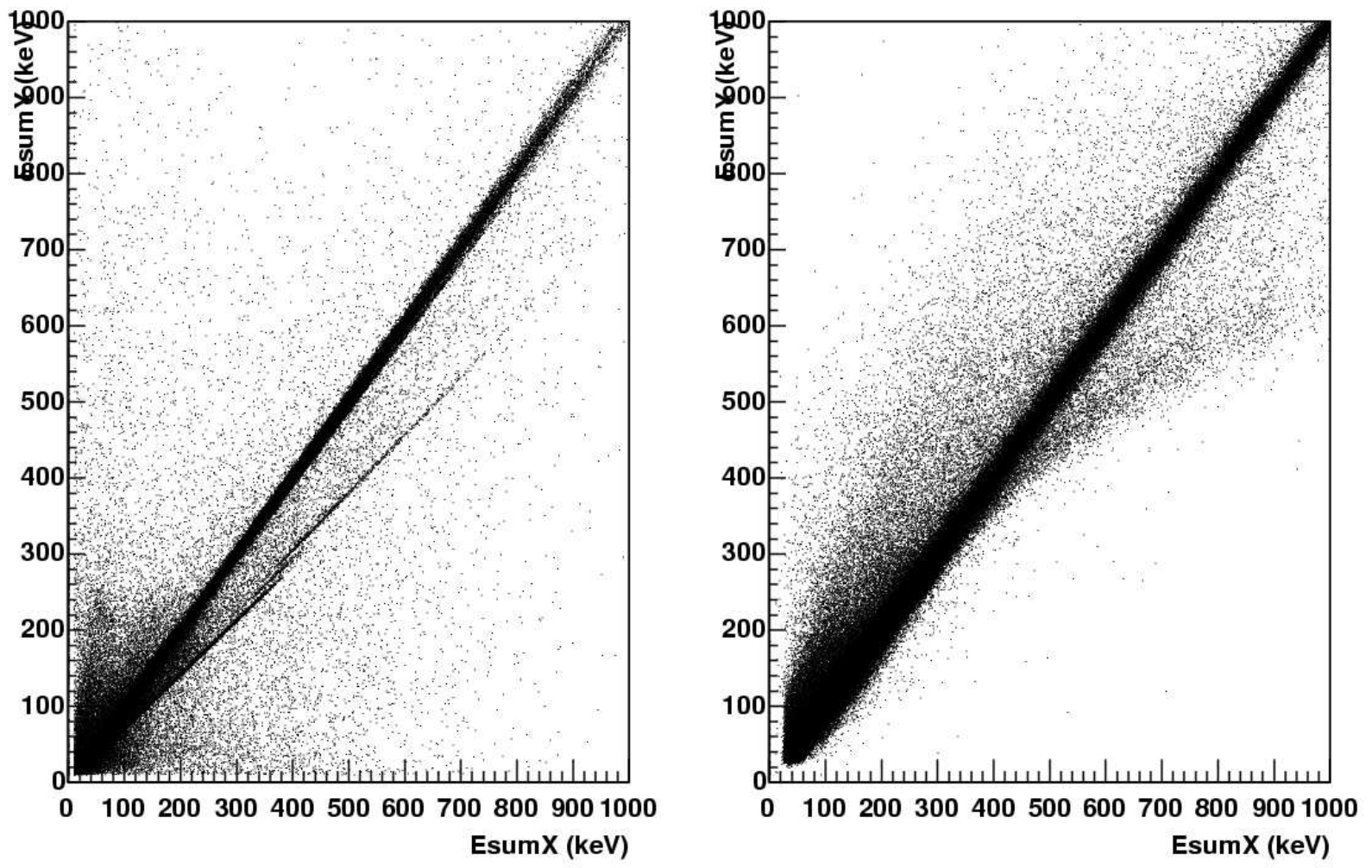

Figure 7: Sum of the energy in $\mathrm{X}$ vs sum in $\mathrm{Y}$ plane for each detector (silicon on the left, germanium on the right). Low-energy strips (below $10 \mathrm{keV}$ ) are excluded.

\section{Energy Sum}

Since the electrons and holes drift to and are collected by opposite sides of the detector, each side should measure the same net energy. Figure 7 shows the energy sum of the X-side compared to the energy sum of the Y-side for each detector. Strips with energy less than $10 \mathrm{keV}$ (i.e., transients - see Section 3) are not included in this energy sum.

Recall that strip 13 on the Y side of the silicon appears to be partially dead (see Figure 1). This shows up as the dark band in Figure 7, where the energy sum in the Y side is consistently less than that from the $\mathrm{X}$ side. Strip 13 on the $\mathrm{X}$ side is also completely dead. These two dead regions result in events in which there is energy only on one side and none in the other. This effect can be seen in the figures by zooming in on the various axes, see Figure 8. Note that the effect appears in the silicon but not the germanium, where it appears that the charge is collected from all strips. 

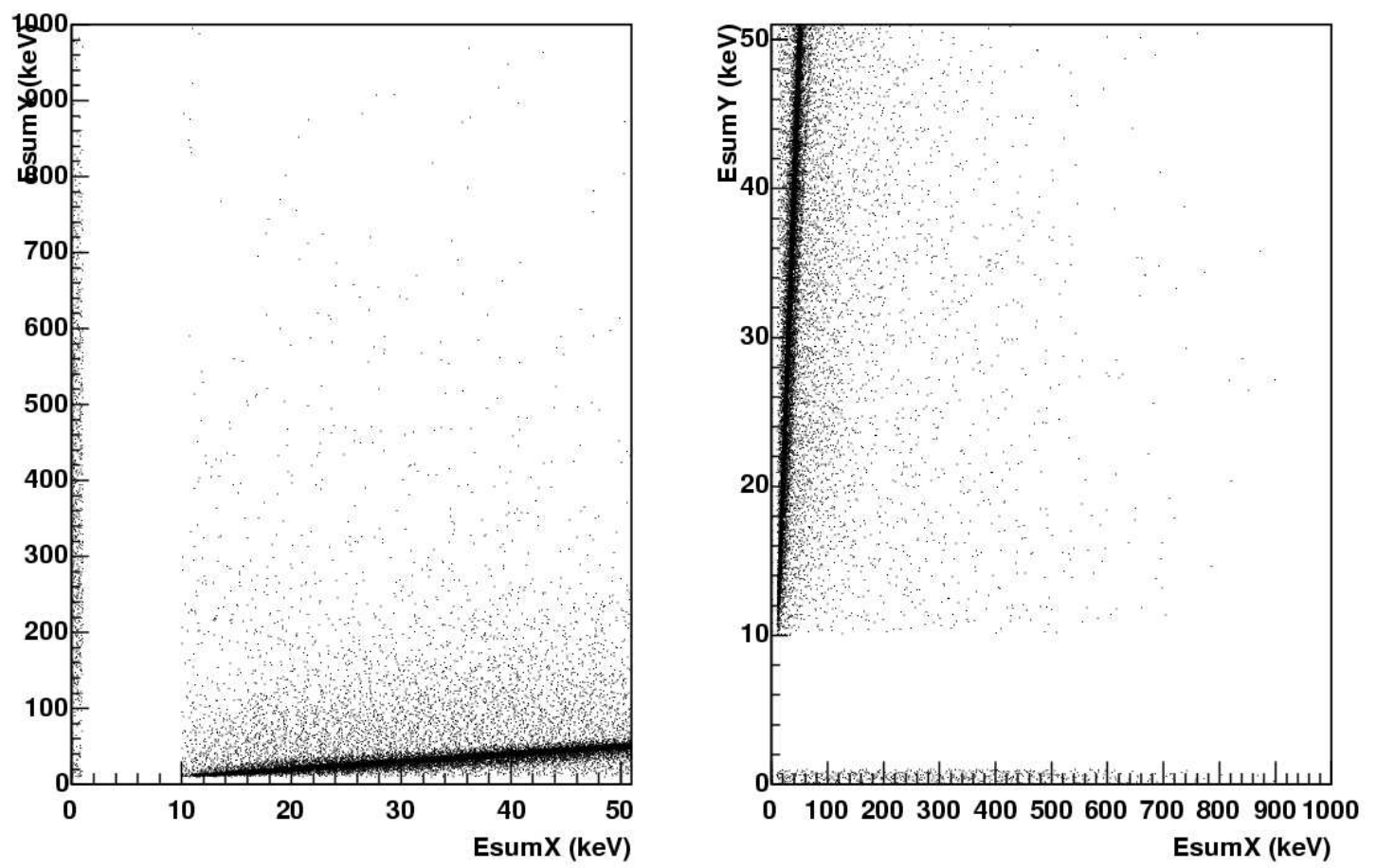

Figure 8: Data in the silicon detector zoomed in on the $\mathrm{X}$ axis (plot on the left) and $\mathrm{Y}$ axis (plot on the right). 